Mid-American Review of Sociology

Swift, Jeremy

The Development of Livestock Trading in a Nomadic Pastoral Economy: The Somali Case in Goldschmidt, Walter, ed., Pastoral Production and Society.

Taylor, T.H. and Templeton, W.C.

Grassland Eco-System Concepts in Heath, Metcalfe and Barnes, eds., Forages.

Terril, Clair E., and Lindahl, Ivan and Price, Donald

Sheep-Efficient Users of Forage in Heath, Metcalfe and Barnes, eds., Forages.

Tietze, U.

1973 "A Matter of Terminology: A Critical Look at Migratory Stock Breeding," Geoforum, Vol. 13.

*Viktarov, S.V., Ata'ev, E.A., and Kalenor, G.S.

1973 "Main Trends and Results of Indicative Investigations of Deserts of the U.S.S.R.," The Soviet Journal of Ecology, Vol. 4, No. 3.

Wallerstein, Immanule

1974 The Modern World System, Vol. I, Capitalist Agriculture and the Origins of the European World Economy in the Sixteenth Century, Academic Press, New York.

Weigmann, Hans-Dietrich

"Fibers, Natural" in Encyclopedia Britannica, Vol. 7 15th ed.

\section{ALTRUISM AND SOCIAL EXCHANGE \\ THEORY: THE VICARIOUS REWARDS \\ OF THE ALTRUIST*}

\section{James M. Honeycut \\ Purdue University}

The position is taken that the altruistic person who is giving a reward to another is in a one-up or dominating position. The person receiving the reward is in a submissive role by virtue of acceptance of the reward. They may even feel that the reward is a cost if they are unable to reciprocate. Equity may enter into the context as the target of the altruism seeks to reestablish balance. While altruistic behavior may not result in immediate reward on the part of the "rewarder," there may be delayed or vicarious reward.

It has been a considerable point of critical debate that social exchange theory and altruistic behavior are diametrically opposed concepts (Chadwick-Jones, 1976:251). If people are seeking to maximize rewards and minimize costs in interpersonal relationships, then how can we account for the variance of altruistic intentions or that helping behavior which is prevalent in some situations such that there appears to be the dispensing of a reward rather than the dispenser receiving a reward. It is the intent of this analysis, to posit that while at one level, altruistic behavior is indeed the giving up of a resource or reward and at another level, it encompasses the receiving of different types of "gifts."

Thibault and Kelley (1959) used the term, "fate control," to refer to a condition where one person has power over another and is in a position to allocate rewards to the self, irrespective of the choice of action by the other. Thus, altruism may be viewed as a situation whereby the actor dispenses rewards to the other and also receives vicarious rewards by virtue of being in a position where resources can be allocated to the other. A person with fate

*I would like to thank Dr. Ralph Webb of the Department of Communication at Purdue University who provided feedback on the writing of this paper. 
control over another can direct to the self a greater share of rewards and decide whether to withhold rewards or make them available.

\section{Generalized Equity Theory}

According to equity theory, individuals try to maximize their profits (Profit $=$ rewards $/$ cost) or minimize deficients (Walster, Berscheid, and Walster, 1973). When a person is in an inequitable relationship by virtue of unequal distribution of resources, the person may become distressed and attempt to restore equity. For example, when a person of perceived high status gives a reward to a lower status person, the lower status person may feel embarrassed and distressed if rewards continue to be dispensed such that the lower status person is in a position where equitable reciprocation is not possible. If a person receives too many rewards, dissatisfaction may result (Baron, 1966) and people who lack the resources to reciprocate may also feel resentful of the rewarder (Gergen, 1969).

The act of rewarding another, can increase self-esteem since the fact of being able to reward B is indicative of A's having the resources for allocation. Consider the case where A helps B such that the relationship becomes inequitable because of B's cumulative indebtedness to A. B can attempt to restore balance by giving $A$ another reward or by justification of the previous helping behavior that $A$ allocated to $B$. If $B$ has the ability to repay, he or she will probably use compensation as the technique of equity restoration; if B doesn't have the ability to repay, he or she might use justification. Triandis (1977) indicates that in interpersonal encounters, interactants are more likely to accept "gifts" that can be reciprocated.

With regards to altruistic behavior by A, B may not perceive such intent as being altruistically motivated. Triandis cites an example whereby $P$ gives $O$ some money, but $O$ perceives the action as a bribe which is not rewarding to $O$. If $A$ gives a reward to $B$ that $B$ is unable to repay, inequity may result and $B$ may not feel rewarded. Thus, altruistic behavior at a superficial level, may not be perceived as rewarding to B at a more covert level. Also, perceptions of rewards and costs are difficult to identify since they are contingent on individual orientation in relation to the other.

\section{Locus of Control}

Kanfer (1979) posits that training people to have an altruistic orientation consists of helping a person to alter the probability of the highly preferred and generally more immediately rewarded response in favor of a response that has an initially lower probability because it is less immediately rewarding or gratifying. Kanfer indicates that a motivational base other than the incentive of benefit for the other must be provided. This means the availability of external support and reinforcement to help the individual to incorporate criteria for altruistic behavior. Social approval or recognition may provide such motivation. Kanfer (p. 237) states with regards to altruistic training that "in a sense, the task, as in self-control, is to train persons to act for the benefits of another because it is in their own self-interest." In and of itself, protection of one's self-interest may either be rewarding or costly in the interim, but in the long term analysis, there may be a higher probability of rewarded response. Altruism may result in delayed return rewards to the initial rewarder such that cost may be incurred immediately after the fact, but the rewards come to negate the cost later on such that there is a perceived profit of rewards over costs.

\section{Determinants of Interpersonal Behavior (Triandis, 1977)}

It has been hypothesized that interpersonal behavior is a function of behavioral intentions and habits. Triandis (1977) posits a formula $(I=W s(S)+W a(A)+W c(C))$ where $I$ refers to intention, $\mathrm{S}$ is social factors such as norms, roles, and contractual arrangements, and $\mathrm{C}$ is perceived consequences as a result of the behavior and the value or affect attached to that consequence. Thus, behavioral intentions are conceptualized as a function of social factors, affect, and the value to the actor of the perceived consequences of the behavior. 
The formula above is designed to predict behavioral intentions which is a component of the probability determinants for an act or behavior. Triandis expresses this formula as: $\mathrm{Pa}=(\mathrm{Wh}$. $\mathrm{H}+\mathrm{Wi} . \mathrm{I}) . \mathrm{F}$. $\mathrm{Pa}$ is the probability of an act, $\mathrm{H}$ refers to the strength of the habit to emit the act, $\mathrm{I}$ is the behavioral intention to emit the act, and $F$ is the individual's ability to emit the act " (facilitating conditions).

The $\mathrm{C}$ component under the intention formula will carry a large weight if altruistic behavior is being considered by the actor. While this has not been empirically tested, there appears to be more than sufficient theoretical foundation to make the hypothesis. The A component should also carry a large weight as the pleasantness of the altruism is considered. Thus, altruism may result in a situation whereby the weighting of the $A$ and $\mathrm{C}$ components in the Triandis model is larger in comparison to the $\mathrm{S}$ component.

\section{Perceived Dimensions of Interpersonal Relations}

Wish, Deutsch, and Kaplan (1976) have found that people generally think of relationships along four major dimensions.

1. Cooperative and Friendly vs. Competitive and Hostile (This dimension was found to be more important for evaluating other's relationships rather than one's own.).

2. Equal vs. Unequal.

3. Intense vs. Superficial (This dimension is more important in evaluating one's own relationships.)

4. Socioemotional and Informal vs. Task-oriented and Formal

The dimensions all interact with one another and in some relationships, one dimension may be more prevalent than the others. For example, spouses are perceived as tending toward equality and being cooperative/friendly, while a parent and child are seen as cooperative/friendly but also as unequal. One could postulate that altruistic intentions are more along a cooperative and friendly continuum. However, the equal/unequal dimensions could have some influence in altruism in that A who is displaying altruism toward $B$, is in a position of dominance (with respect to the resource given) by virtue of the dissemination of the resource. Future research is needed to examine perceived dimensions of altruistic behavior which has been hypothesized here.

Millar and Rogers' Dimension of Dominance

Millar and Rogers (1976) define control as being concerned with "who has the right to direct, delimit, and define the actions of the interpersonal system in the presently experienced spatiotemporal situation." In essence, the argument is made that dominance is concerned with the amount of time that a person asserts relational definitions to the other in which the other accepts.

A person is said to be in a one-up position when he or she attempts to assert definitional rights and a person is in a onedown position when they request or accept the other's definition. It is possible that the transactional codes of an altruistic intention could be conceptualized as one-up. One-down would characterize an altruistic person in a position to assert a relational definition. Thus, the person who is the target of the altruism, accepts the resource and the definition whereby he or she is in a one-down position or in a submissive role. Attempts to restore equity and exhibit more one-up moves may follow if the facilitating conditions are present or where the altruism can effectively be reciprocated. Exchanges of upward or downward movements may be seen as attempts to maintain or achieve equilibrium and equity. In some . .

situations, too many upward movements may destroy equity such that perceptions of an altruistic intention, that $A$ has toward $B$, may be perceived as costly to $B$ and thus no attribution of altruism is made in regards to $A$ 's original intention.

Implications and Conclusions

Altruism can be included under the auspices of social exchange theory. Limitations to its application involve concrete definitions of rewards or resources and whether immediate gratification is necessary. The rewards to two individuals may be 
clearly separable since the welfare of one person provides a reward to the other and that one can be concerned with one's own and another's welfare (Sawyer, 1966).

Berkowitz and Friedman (1967) suggest that altruism will be facilitated if it has been the person's previous experience that he or she has also been helped in a smiliar situation. While exchange theory and altruistic behavior may appear at one level to be opposing concepts, there is a possibility of compatible integration. Behaviors that are done without hope of return benefits may be explained as deriving pleasure from past benefits that one has received from others when he or she was in a position of dependency (e.g., the loaning of money to a friend or for that matter to anyone such as in charitable actions).

People who are targets of altruism are in a position of dependency with regard to accepting the given resource. Thus, the one imparting the resource is vicariously rewarded. At the minimum, they are in a one-up position if the altruism is perceived. It has been stated that "appeals to altruism, like inducements, acknowledge one's indebtedness to the other, thus offering him status or power," (Blau, 1955:189). If this is true, the question then involves deciding whether status or power is rewarding considering that rewards and costs are difficult to analyze cross-situationally.

It was discussed how equilibrium may be an intervening variable in determining perceptions of altruistic intentions. The target of the altruism may try to reestablish equity if there was a state of perceived equity before the altruist act or series of acts. While altruistic behavior may not result in immediate reward on the part of the "rewarder," there may be delayed payment as well as vicarious rewards. It is hoped that future research endeavors will analyze altruism along with social exchange theory in view of some of the hypotheses that were theoretically formulated in this paper. As we learn more about such phenomena, we will receive rewards in the form of gained knowledge by the fruits of our own research.

\section{REFERENCES}

Baron, R.

1966 "Social reinforcement effects as a function of social reinforcement history." Psychological Review 73:527-539.

Berkowitz, L. and Friedman, P.

1967 "Some social class differences in helping behavior." Journal of Personality and Social Psychology 5:217-225.

Blau, P.M.

1955 The Dynamics of Bureaucracy: A Study of Interpersonal Relations in Two Government Agencies. Chicago: University of Chicago Press.

Chadwick-Jones, J.K.

1976 Social Exchange Theory: Its Structure and Influence in Social

Gergen, K.J. Psychology. New York: Academic Press, Inc.

1969 The Psychology of Behavior Exchange. Reading, Mass.: Addison-

Kanfer, F.H. Wesley.

1979 "Personal control, social control, and altruism." American Psychologist 34:231-239.

Millar, F.E. and Rogers, L.E.

1976 "A relational approach to interpersonal communication." Pp. 87-104 in G.R. Miller (ed.), Explorations in Interpersonal Communication. Beverly Hills: Sage Publications, Inc.

Swayer, J.

1966 "The altruism scale: A measure of cooperative, individualistic, and competitive interpersonal orientation." American Journal of Sociology 71:407-416.

Thibault, J. and Kelley, H.H.

1959 The Social Psychology of Groups. New York: Wiley and Sons.

Triandis, H.C.

1977 Interpersonal Behavior. Monterey, Ca.: Brooks/Cole Publishing Company.

Walster, E., Berscheid, E., and Walster, W.

1973 "New directions in equity theory." Journal of Personality and Social Psychology 26:113-126.

Wish, M., Deutsch, M., and Kaplan, S.J.

1976 "Perceived dimensions of interpersonal relations." Journal of Personality and Social Psychology 33:409-420. 